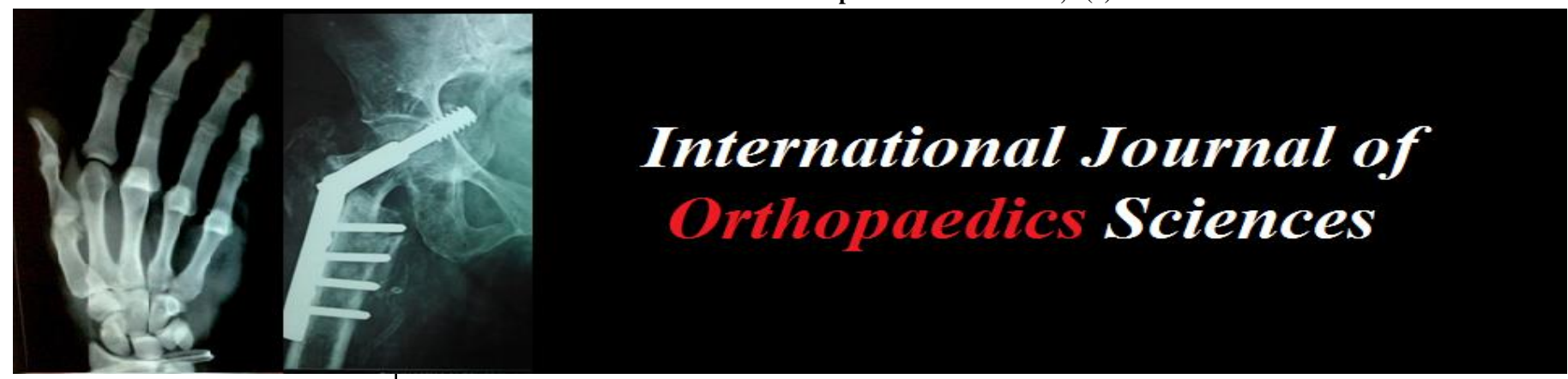

ISSN: $2395-1958$

IJOS 2019; 5(2): 907-910

(C) 2019 IJOS

www.orthopaper.com

Received: 24-02-2019

Accepted: 28-03-2019

Anil Gupta MS

Prof \& HOD, Government

Medical College, Jammu, Jammu

and Kashmir, India

Shafiq Hackla MS

Senior resident, Government

Medical College, Jammu, Jammu

and Kashmir, India

John Mohammad

Junior resident, Government

Medical College, Jammu, Jammu

and Kashmir, India

\section{Naresh Rana}

Junior resident, Government

Medical College, Jammu, Jammu

and Kashmir, India

\section{Kamalji Pandit}

Junior resident, Government

Medical College, Jammu, Jammu

and Kashmir, India

\section{Shujat Ali}

Junior resident, Government

Medical College, Jammu, Jammu and Kashmir, India
Correspondence

Anil Gupta MS

Prof \& HOD, Government

Medical College, Jammu, Jammu

and Kashmir, India

\section{Management of distal femur fractures with bicolumnar fixation with condylar buttress plate and TENS nail}

\author{
Anil Gupta MS, Shafiq Hackla MS, John Mohammad, Naresh Rana, \\ Kamalji Pandit and Shujat Ali
}

DOI: $\underline{\text { https://doi.org/10.22271/ortho.2019.v5.i2m.110 }}$

\section{Abstract}

Introduction: The fracture of distal femur are often unstable and comminuted and as difficult to treat. The incidence of complications in these fracture are relatively high. We have treated the fracture of distal femur with comminuted medial wall with condylar buttress plate and support of medial wall with TENS nail.

Material and Methods: Fifty three patients with intercondylar fracture of distal femur were selected. There were thirty three males and twenty females. The average age of the patients was 36.2 years. All the patients were operated between 3 to 7 days. The final outcome was assessed according to schatzker and Lambert scoring system. The complications were also noted.

Results: The result was excellent in fifteen, good in twenty three, fair in eleven and poor in four patients according to schatzker and Lambert scoring system. The average time to Union was 14.2 weeks. Complications include superficial wound infection in five patient, knee stiffness, and varus angulation less than 5 degree in eight and five patients respectively.

Conclusion: The use of TENS nail for medial femoral defect along with condylar buttress plate may eliminate the need of plate on medial side. The varus angulation that occurs with defect is decreased and additional long incision and operative time is avoided.

Keywords: TENS nail, varus angulation, medial femoral defect

\section{Introduction}

The fractures of distal femur are usually the result of high energy trauma. They are often very severe and difficult to treat. The incidence of these fractures is $0.4 \%$ of all fracture and $3 \%$ of femoral fracture. There is bimodal distribution with highest in woman older than 75 years and adolescent boys and men 15 to 24 years old. Because of proximity of these fractures to knee joint, regaining full knee motion and function may be challenging.

The treatment of distal femur fractures have evolved from non-operative to operative to fixation of both lateral and medial columns of femur ${ }^{[1]}$. The goal of these techniques is to restore anatomical reduction of the joint, stable fixation and to prevent varus or valgus angulation. The high incidence of complications with both column fixations with plates discouraged its use [2]. The purpose of our study to evaluate the efficacy of both column fixations by using condylar buttress plate on lateral side and then using TENS nail on medial side to obtain support of medial column and prevent varus angulation.

\section{Methods and Materials}

A prospective study was conducted in GMCH, Jammu from June 2012 to July 2015. Fifty three patients with comminuted intercondylar fracture of femur were operated. There were thirty seven males and sixteen females. The average age of the patients was 36.22 years the oldest being 56 years old and youngest being 23 years. The forty patients were having road traffic accident and twelve patients were having fall from height. One patient was having implant failure after fall. All the patients were operated within a week after they were hemodynamically stable. The detailed preoperative planning and evaluation was done. Fig 1 . 


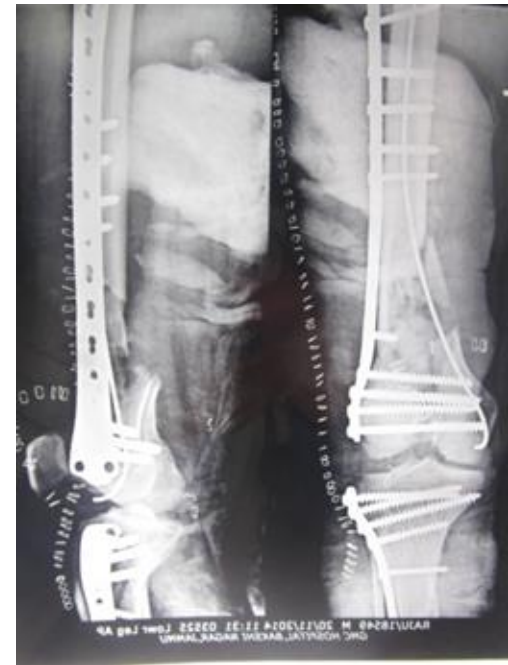

Fig 1: Shows immediate postop radiograph condylar buttress plate on lateral side and TENS nail on medial side 2(A) Approach

The swashbuckler approach was used ${ }^{[3]}$. The patient was placed supine on radiolucent fracture table. An incision was made in the midline of thigh from above the fracture laterally to across the patella. The vastus lateralis muscle was retracted medially after lateral para-patellar arthrotomy was made. Condylar fragments were reduced, stabilised and then minimally fixed with condylar buttress plate on lateral side (two screws distally and only one screw proximally). The amount of varus angulation was also corrected during the procedure.

By using C- arm guidance, a two $\mathrm{cm}$ incision made over medial aspect of distal femur. Entry portal was made with the help of curved awl. An appropriate size TENS nail was then fixed from medial side into the medullary canal of the femur. The final position was then checked under $\mathrm{C}$-arm guidance and remaining screws were put to fix the lateral plate. The wound was then closed in layers and antiseptic dressing was applied Fig 2.

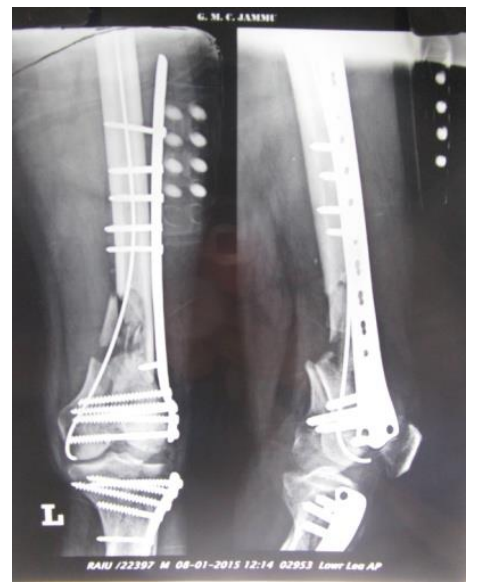

Fig 2: Shows radiographs at 6 weeks follow up with fracture ccallus and consolidation

\section{2(B) Rehabilitation Protocol}

The POP back slab was applied for initial 3 to 4 days. Drains were removed on first dressing. On 4th post-operative day, range of motion and quadriceps strengthening exercises were started. The patient was allowed to walk with a pair of crutches and bear partial weight bearing till they achieved good quadriceps power and radiological examination revealed fracture unionfig 3,4 .
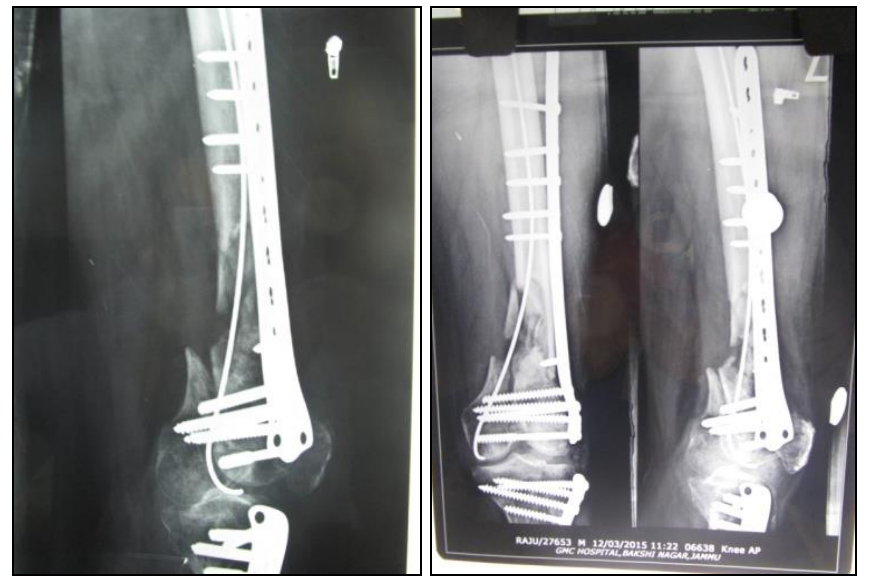

Fig 3, 4: Sows radiograph at 3 months follow up, consolidation of fracture surfaces and slight loss of reduction with posterior angulation

The final outcome was assessed using schatzker and Lambert scoring system which is excellent if full extension, no varus or valgus deformity, no pain and prefect joint congruity is present. Good result includes not more than one of following like loss of length not more than $1.2 \mathrm{~cm}$, less than $10^{\circ}$ varus or valgus deformity, flexion loss more than $20^{\circ}$ and minimal pain and failure when flexion to $90^{\circ}$ or less, varus or valgus more than $15^{\circ}$, joint incongruity and disabling pain ${ }^{[4]}$. The following were noted at six month follow up. Clinical union, range of motions at knee joint, power, and mobility of quadriceps, walking distance, radiological union, any limb length discrepancy, total time for union and complications fig 5. The average operative time, amount of blood loss and infection rate was also noted.

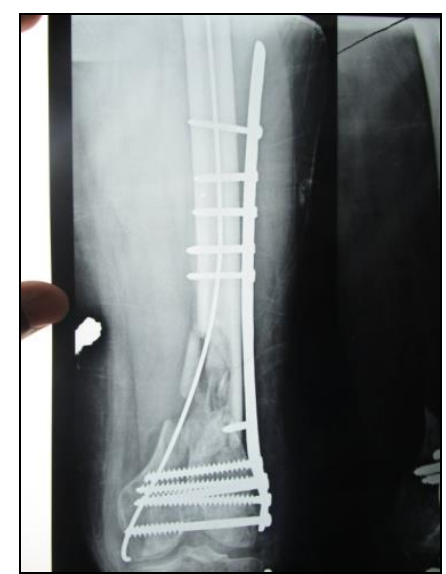

Fig 5: Shows good healing response at 6 month follow up.

\section{Result}

The average operative time was 92 mins and average union time was 14.2 weeks. The number of patients according to AO/OTA classification was thirty seven in type $\mathrm{C}$ and sixteen in type B. Fracture was considered united when patient was full weight bearing, had no or minimal pain and on radiograph at least three cortices were united.(Table.1)

Table 1: Shows average union time

\begin{tabular}{|c|c|c|}
\hline Time taken & No. of cases & Percentage (\%) \\
\hline 10 weeks or less & 0 & 0 \\
\hline $11-14$ weeks & 36 & 68 \\
\hline $15-20$ weeks & 15 & 28 \\
\hline More than 20 weeks & 2 & 4 \\
\hline Total & 53 & 100 \\
\hline
\end{tabular}


Complications include superficial wound infection in five patients, minimal pain in ten patients, varus angulation less than 5 degree in seven patients. The range of motion greater than 90 degree was present in thirty six patients while seventeen patients were having ROM less than 90 degree. (table.2).

Table 2: Shows the range of movement of knee joint

\begin{tabular}{|c|c|}
\hline Range of movement $\left({ }^{\circ}\right)$ & No. of patients \\
\hline $0-30$ & 3 \\
\hline $31-60$ & 4 \\
\hline $61-90$ & 10 \\
\hline $91-120$ & 15 \\
\hline $121-140$ & 21 \\
\hline Total & 53 \\
\hline
\end{tabular}

The final outcome was evaluated using schatzker and Lambert scoring system which was excellent in fifteen patients, good in twenty three, fair in eleven and poor in four patients.(table.3).

Table 3: Shows result according to schatzkar and Lambert scoring system

\begin{tabular}{|c|c|c|}
\hline Results & No. of cases & Percentage (\%) \\
\hline Excellent & 15 & 29 \\
\hline Good & 23 & 43 \\
\hline Fair & 11 & 21 \\
\hline Poor & 4 & 7 \\
\hline Total & 53 & 100 \\
\hline
\end{tabular}

\section{Discussion}

Current fracture patterns veer towards complex comminuted type due to prevalence of high energy trauma. The violent nature of injury in young individuals who sustain high velocity during road traffic accident and osteoporotic bones in elderly patients make single column fixation unsatisfactory option ${ }^{[5]}$. The goal of treatment is to achieve bone healing and restore function of the affected limb in shortest possible time without compromising stability ${ }^{[6]}$.

The distal femoral fractures has been classified by Muller (AO) into extra-articular, partial articular and intra-articular types ${ }^{[10,11]}$. We have based our study on intraarticular type $C$ fractures which are generally associated with severe comminution and bony loss. The mode of trauma in distal femoral fractures is usually severe varus, valgus or rotational force with axial loading sustained in young as result of high energy trauma as in road traffic accident and in elderly as result of minor slip or fall on flexed knee. In intercondylar fractures, there will be rotational malaligment because of separate attachments of gastrocnemius muscle to each condyle.

Complications of distal femoral fractures include malunion, nonunion, varus angulation, limb length discrepancy, infections and secondary osteoarthritis of patellofemoral and tibiofemoral joints. The principle of treatment in these fracture include restoration of bony continuity, maintance of good reduction, articular congruity, and good range of movements ${ }^{[7]}$. These fractures earlier treated nonsurgically were associated with angular deformity, joint incongruity, knee stiffness and delayed patient mobilisation. The different fixation devices used include angle blade plate (schatzker 1979), rush rods (Shelbourne1981), enders nail (Kolmert 1986) and zickel device. However, these devices were technically demanding and didn't achieve rigid fixation of articular surface ${ }^{[8,13]}$. Dual plating used in comminuted fractures often result in extensive soft tissue stripping on both sides of femur resulting in reduced blood supply, delayed or nonunion and failure of implant. Callus formation was inconsistent and irregular with these plates ${ }^{[9,12]}$.

The average union time was 13.8 weeks in Markmiller et al. study while it is 14.2 weeks in our study ${ }^{[15]}$. No evidence of disability was nited in our study which is comparable to the study of Schultz et al. ${ }^{[16]}$. The advantages of fixation includes active range of motions can be started earlier, maximum range of motion is preserved, stable internal fixation does not allow malunion to occur, maintenance of articular congruity and incidence of implant failure and hospital stay is reduced ${ }^{[17]}$.

\section{Acknowledgement: None}

\section{Conflict of interest: None}

\section{References}

1. Foster MC, Komarsamy B, Davison JN. Distal femoral fractures: A review of fixation methods. Injury. 2006; 37:97-108.

2. Johnstone A, Carnegie C, Christie, McCollaugh J. The challenges associated with treating distal femoral fractures with distal femoral locking plate in elderly: Different pattern of failure in different locking plates. $\mathrm{J}$ bone J surg (Br). 2010; 92(4):550.

3. Frankhauser F, Gruber G, Schippinger G, Christian B, Hofer HP, Grechening W et al. Minimally invasive treatment of distal femoral fractures using LISS. A prospective study of 30 patients with follow up upto 20 months. Acta Orthop Scandal. 2004; 75(1):56-60.

4. Malik I, Khan R, Khurana R, Sharma S. Comparative study of management of distal femur fractures managed by dynamic condylar screw and distal femoral locking plate. Orthopaedics. 2015; 6(9):WMC004976.

5. Wahner KL, Hoffmeier KL, Vonoldenberg G. Internal fixation of type $\mathrm{C}$ distal femoral fractures in osteoporotic bones. JBJS (Am). 2011;93:40-54

6. Ezekiel TSL, Balogh ZJ. Indications and limitations of locking plate. Injury. 2009; 40(7):683-693.

7. Syed AA. Distal femoral fractures: long term outcome following stabilization with LISS. Injury. 2004; 35(6):599-607.

8. Wahnert D, Hoffmier KL, Frober R, Hoffman GO, Muckley T. Distal femur fractures of the elderly-different treatment options in a biomechanical comparison. Injury 2011; 42:655-59.

9. 9.. Lujan M, Trevor J, Henderson W. Locked plate for distal femur fractures leads to inconsistent and irregular callus formation. J Orthop Trauma, 2010; 24(3):156-162.

10. Jahangir AA, Cross WW, Schmidt AH. Current management of distal femoral fractures. Current orthopaedic practice. 2010; 21:193-97.

11. Gwathmey FW Jr, Jones-Quaidoo SM, Kahler D, Hurwitz S, Cui Q. Distal femoral fractures: current concepts. J Am Acad Orthop Surg. 2010; 18:597-607.

12. Henderson CE, Kuhl LL, Fitzpatrick DC, Marsh JL. Locking plates for distal femur fractures: Is there a problem with fracture healing? J Orthop Ttrauma. 2011; 25:S8-S14.

13. Beingessner D, Moon E, Barei D, Morshed S. Biomechanical analysis of the less invasive stabilization system for mechanically unstable fractures of the distal femur: comparison of titanium versus stainless steel and bicortical versus unicortical fixation. J Trauma. 2011; 
71(3):620-4.

14. Hoffman MF, Jones CB, Sietsema DL, Koeing SJ. Clinical outcome of locked plating of distal femoral fractures in a retrospective cohort. Journal of orthopaedic surgery and research. 2013; 8:43.

15. Markmiller M, konard G, Sudkamp N. Femur- LISS and distal femoral nail for fixation of distal femoral fractures. Clin Orthop. 2004; 426:252-7.

16. Schutz M, Muller M, Regazzoni P. Use of less invasive stabilization system in patients with distal femoral fractures: A prospective multicentric study. Acta Orthop Trauma. 2005; 125(2):102-8.

17. Smith TO. The clinical and radiological outcomes of the LISS plate for distal femoral fractures: A systemic review. Injury Int. Care Injured, 2009. 